\title{
Menisküs tamiri sonuçları
}

\section{Outcomes of meniscal repair}

\author{
Osman Tecimel ${ }^{1}$, Ahmet Fırat ${ }^{1}$, Nevzat Reha Tandoğan ${ }^{2}$ \\ ${ }^{1}$ Atatürk Eğitim ve Araştırma Hastanesi, Ortopedi Kliniği, Ankara, Türkiye \\ ${ }^{2}$ Çankaya Ortopedi, Ankara, Türkiye
}

\begin{abstract}
Menisküslerin biyomekanik işlevlerinin anlaşılması ve onarım tekniklerinin gelişmesi ile, menisküsü koruma çabalarının önemi artmıştır. En iyi menisküs tamir sonuçları genç hastaların travmatik, damarlı bölgeye komşu, vertikal longitudinal yırtıklarında elde edilir. İyileşen menisküsün, dizi osteoartrit gelişiminden koruduğu gösterilmiştir. Ön çapraz bağ (ÖÇB) yırtığına eşlik eden menisküs yırtıklarının, bağ rekonstrüksiyonu sırasında onarılması ile \%90'ın üzerinde başarılı sonuçlar elde edilmiştir. İzole menisküs yırtıkların tamirinin başarı oranları biraz daha düşüktür. Son yıllarda menisküs tamir endikasyonları genişletilmiş, radyal, horizontal ve kök yırtıklarında da onarım teknikleri geliştirilmiş ve başarılı sonuçlar elde edilmiştir. Özellikle mediyal menisküs kök yırtıklarının onarımının, dizdeki osteoartirti geciktirmek açısından önemi büyüktür. ÖÇB yırtığına eşlik eden lateral menisküs kök yırtıklarının onarımı, pivot-shift fenomeninin azaltılmasına katkıda bulunur. Dizilim bozukluğu veya bağ instabilitesinin menisküs yırtığına eşlik ettiği durumlarda, kombine girişimlerle hem dizilim bozukluğu hem de instabilite düzeltilmelidir. Menisküs onarımının değerlendirilmesinde klinik muayene ve standart manyetik rezonans (MR) görüntüleme teknikleri yeterli değildir; ikincil artroskopiler veya MR-artrografi ile doğruluk arttırılabilir.
\end{abstract}

Anahtar sözcülkler: menisküs onarımı sonuçları; menisküs yırtıkları; artroskopik menisküs tamiri; menisküs implantları
Advances in the understanding of the biomechanical role of the menisci and repair techniques have led to an increased effort to preserve the menisci. The best results of meniscal repair are obtained in traumatic vertical longitudinal tears in the vascular zone in younger patients. It has been shown that healed menisci can protect the knee from osteoarthritic changes. Meniscal repairs accompanying anterior cruciate ligament ( $A C L)$ injuries have up to $90 \%$ healing rates. Isolated meniscal repairs have slightly inferior outcomes. Developments in surgical technique and instrumentation have led to expanded indications for meniscal repair including horizontal, radial and root tears of the menisci. Repair of the degenerative medial meniscal root tears is important to prevent rapid progression of osteoarthritis. Repair of the lateral meniscal root tears accompanying ACL tears contributes to the decrease of pivot-shift phenomena. If malalignment of the extremity or ligamentous laxity accompanies a meniscal tear, both should be corrected with combined interventions. Clinical examination and standard magnetic resonance imaging (MRI) does not provide adequate information to evaluate the healing of meniscal repairs; second look arthroscopy or arthro-MRI can improve accuracy.

Key words: meniscal repair outcomes; meniscal tear; arthroscopic meniscal repair; meniscal implants

sorunlardan biri olan menisküs yırtıklarının tamir endikasyonları, komplikasyonları ve sonuçlarından kısaca bahsedilmiştir.

\section{ENDIKASYONLAR}

Stabil bir dizdeki menisküs yırtığının teşhisinde en önemli yardımcılar, yırtığın öyküsü ve fizik muayene bulgularıdır. Çok şüphede kalınan durumlar veya eşlik eden patoloji varlığında, yardımcı görüntüleme yöntemlerine başvurulabilir. Menisküs lezyonunun

- Illetişim adresi: Prof. Dr. Nevzat Reha Tandoğan, Ortoklinik ve Çankaya Ortopedi, Cinnah caddesi 51/4 Çankaya, 06680, Ankara Tel: 0312 - 43902 06-08 e-posta: rtandogan@ortoklinik.com

- Geliștarihi: 1 Mart 2018 Kabul tarihi: 1 Mart 2018 
en iyi bilinen oluş mekanizması, fleksiyon-dış rotasyon manevrası ile oluşan travmadır. Bu yaralanmanın, diz çökme veya çömelme konumundan doğrulma esnasında olması, kova sapı yırtık oluşumunu güçlendirir. Dejeneratif yırtıklar ise, biyomekanik dayanıklılığı azalmış menisküsün yapısal zayıflığından kaynaklanan ve menisküsün büyük oranda genelini tutan dejenerasyon sonucu oluşmuş muhtelif boylardaki yırtıklardır. Kas güçlendirmesi ve fizyoterapinin bu yırtıklarda klinik sonuçları düzelttiği gösterilmiştir. ${ }^{[3]}$ Dejeneratif yırtıklarda cerrahi tedavi yaklaşımlarının konservatif tedavilerden üstün olmadığı gösterilmiştir. ${ }^{[4]}$

Konservatif takip edilebilecek yırtıklar; menisküsün iç halkasının sağlam olduğu tam kat olmayan yırtıklar ile 5 mm'den küçük tam kat vertikal veya oblik yırtıklardır. ${ }^{[5]}$ Yine, 5 mm'den küçük radyal yırtıklar da bu kapsamda değerlendirilir. Bu radyal yırtıklar iyileşmese de, genellikle asemptomatik seyretmektedir. ${ }^{[6]}$ Stabil uzunlamasına yırtıklar, $5 \mathrm{~mm}$ 'nin altında ise yine konservatif olarak takip edilebilir. Tam kat olmayan arka boynuz yırtıkları, sıklıkla ön çapraz bağ yaralanmalarına eşlik eder. Lateral menisküste yer alan ve bağ cerrahisi sırasında stabil olduğu saptanan bu yırtıklar konservatif olarak tedavi edilebilir; aynı yırtıkların mediyal menisküste olanlarının iyileşme yeteneği daha azdır ve cerrahi tedavi edilmelidir. ${ }^{[7]}$

Menisküs yırtıklarının cerrahi olarak onarılmasında en önemli kıstas yırtık yerleşimidir. DeHaven, menisküsün $3 \mathrm{~mm}$ 'lik periferinin damarsal yönden zengin olduğunu göstermiştir. ${ }^{[8]} \mathrm{Bu}$ beslenmesi zengin bölgedeki $1 \mathrm{~cm}$ 'den büyük yırtıklar, cerrahi tamir için ideal bir endikasyon oluşturur. Menisküs beslenmesinin az olduğu bölge yırtıklarında eksojen fibrin pıhtısının kullanımı, menisküs tamirlerinde iyileşme cevabını arttırmada etkili olarak kullanılmaktadır. ${ }^{[9]}$ Yırtık tipi de onarım endikasyonlarını etkiler. Menisküsün çembersel (hoop) liflerinin sağlam olduğu yırtıklar, tamir için uygun patolojilerdir. Dolayısıyla radyal yırtıklar tamir için daha az elverişli yaralanmalardır. Yine, yırtık kompleks ise tamir sonuçları olumsuz etkilenir. Kronik yaralanmalarda görülen radyal komponentin eşlik ettiği kompleks kova sapı yırtıklar, basit kova sapı yırtıklara göre tamir sonrası daha az iyileşmektedir. ${ }^{[5]}$ Menisküs cismindeki yapısal bozukluk da menisküs tamir sonuçlarını olumsuz etkiler. Kronik dönemde deplase kalmış menisküs yapılarında gelişen fibrozis ve deformasyon, gerek beslenmeyi bozarak, gerekse de redüksiyonu engelleyerek, yapılacak tamirin iyileşme ihtimalini azaltır. ${ }^{[10]}$ Menisküs yırtıklarının, özellikle profesyonel sporcularda olmak üzere, akut dönemde tamir edilmeleri daha iyi sonuç vermektedir. ${ }^{[11]}$
Sgaglione ${ }^{[12]}$, değişik menisküs yırtık tipleri için tamir yöntemlerini şöyle sınıflandırmıştır:

- Dıştan içe tamir: Ön boynuz yırtıkları, orta 1/3 yırtıkları, radyal yırtıklar, kompleks yırtıklar ve kova sapı yırtıkların redüksiyonu için kullanılır.

- İçten dışa tamir: Arka boynuz yırtıkları, orta 1/3 yırtıkları, deplase kova sapı yırtıklar, periferal kapsüler yırtıklar ve meniskal allogreftler için uygundur.

- Menisküs tamir implantları (birinci nesil): Arka boynuz yırtıkları, 2-3 mm'den fazla çeper kalınlığına sahip yırtıklar ve vertikal/longitudinal yırtıklarda kullanılabilir.

- İkinci nesil menisküs tamir implantları (implant dikiş kombinasyonları): Arka boynuz yırtıkları, orta $1 / 3$ yırtıkları, kova sapı yırtıklar, radyal (ışınsal) yırtıklarda kullanılabilir.

\section{İnstabil Dizlerde Menisküs Yırtıkları}

İnstabil dizlerde menisküs yırtıklarının iki ana nedeni vardır. Birincisi, ilk yaralanma sırasında ortaya çıkan eşlik eden lezyon şeklinde, ikincisi ise kronik instabiliteye bağlı sekonder yaralanma olarak görülür. Ön çapraz bağı (ÖÇB) kopuk dizde menisektomi, erken dönemde fonksiyonel sonuçlar ve geç dönemde artritik değişiklikler açısından, stabil bir dize göre daha kötü sonuçlara sahiptir. ${ }^{[13]}$ Dolayısıyla, menisküs tamiri için tüm şartlar zorlanmalıdır. Çapraz bağ yaralanmalarına eşlik eden menisküs yırtıkları daha çok vertikal seyirli ve periferal yerleşimlidir. Bu yırtıklar, ideal tamir endikasyonu oluşturur ve mutlaka tamir edilmelidir. Ayrıca, ÖÇB rekonstrüksiyonu sırasında açılan tünellerden ekleme ulaşan mezenkimal kök hücrelerin menisküs onarımını olumlu etkilediği düşünülmektedir; bu nedenle, tamir endikasyonları genişletilerek uygulanabilir. ÖÇB yırtığına eşlik eden oblik, radyal veya kök yırtıklarının da onarılması, dizin stabilitesini arttıracaktır.

Menisküs iyileşmesi için ön şartlardan biri de, dizin stabilitesinin sağlanmış olmasıdır. Bu nedenle, instabil dizlerde bağ cerrahisi yapılmadan sadece izole menisküs onarımı yapılmasının bilimsel temeli yoktur ve kaynak israfi ve ek morbidite yaratılmasına sebep olur. Bu yırtıklar iyileşmeyeceği gibi, kısa sürede tekrar yırtılacaktır.

\section{MENISKÜS TAMIRLERININ KULLANILAN TEKNIKLERE GÖRE SONUÇLARI}

\section{İçten-Dışa ve Dıştan-İçe Teknikle Tamir Sonuçları}

Literatürde, artan sayılarda yapılan çalışmalara rağmen ideal teknik üzerinde bir fikir birliği bulunmamak- 
tadır. Bu teknikler içerisinde ilk kullanılanı içten-dışa tekniğidir. Portallerden yerleştirilen kılavuz kanüllerden geçirilen 2-0 kalınlığında iplerle, yırtığın oryantasyonuna göre, dikişler menisküs yırtık dudaklarından geçilir. Menisküsü dengeleyecek şekilde alt ve üst yüzünden $5 \mathrm{~mm}$ aralıklarla, vertikal, horizontal veya oblik yerleşimli dikişler yerleştirilebilir. Kapsül dışına alınan iplikler, küçük bir kesi ile kapsül üzerinde bağlanarak tespit edilir. Bu kesiler mediyalde ve lateralde gastroknemiusun, sırasıyla mediyal ve lateral başları yanından açılır. Safen sinir ve daha nadir olarak peroneal sinir hasarı riski vardır. İplikler diz ekstansiyona yakın bir açıdayken bağlanmalıdır; fleksiyonda bağlanan iplikler kapsülü sıkıştırarak diz hareketini engelleyebilir. İçten-dışa tekniği, bugün için menisküs tamirlerinde altın standart tedavi olmasına rağmen, arka boynuz yırtıkları için çok elverişli değildir. ${ }^{[14]}$ Özellikle lateral menisküsün popliteal tendonunun mediyaline geçen yırtıklarda, içten dışa dikişler ile damar-sinir yaralanması riski yüksektir ve ipliklerin kapsül dışına alınması ve bağlanması zordur. Öğrenme eğrisi diğer tekniklere göre daha uzundur ve cerrahi sırasında bir asistan gerektirir.

Dıştan-içe teknikler, her iki menisküsün ön boynuzlarını ilgilendiren yırtıklar için idealdir. ${ }^{[15]}$ Orta 1/3 kesim yırtıklarında da uygulanabilir ama bu bölgede içten-dışa teknikler daha uygundur. Arka boynuzları ilgilendiren yırtıklar, dıştan-içe teknik için uygun değildir; hem yaklaşma açısı uygun olmaz hem de damar-sinir yaralanması riski çok yüksektir. Bu teknik, içten-dışa tekniği kadar geniş kesiler gerektirmez. Bu tamir tekniklerini karşılaştıran ileriye dönük çalışmalar, her iki teknik için de başarılı sonuçlar bildirmiştir. Bu konuda en geniş meta-analizlerden birini yayımlayan Grant ve ark., içten-dışa tekniği ile \%17 oranında tamir başarısızlığı ve takiplerinde yaklaşık 87,8'lik Lysholm skoru bildirmişlerdir. ${ }^{[16]}$ Yine, klinik skorlar açısından içten-dışa tekniği ile tamamı içeride teknikler arasında da bir fark olmadığını ortaya koymuşlardır. Albrecht-Olsen ve ark., içtendışa teknikle tamamı içeride menisküs oklarını karşılaştırdıkları çalışmada, cerrahi sürenin içten-dışa teknikle iki kat fazla olduğunu göstermişlerdir. Cerrahi sürenin azaltılmasının, tamamı içeride tekniklerde kullanılan implantların maliyetini karşılayacağını ileri sürmüşler ve ikinci bakış artroskopi ile değerlendirdikleri iyileşmenin iki grup arasında farklı olmadığını göstermişlerdir. ${ }^{[17]}$ Abdelkafy'nin ortalama 12 yıllık takiplerinde dıştan-içe tekniği ile tamir ettiği menisküs yırtıklarında hastaların $\% 12$ 'sinde sonradan parsiyel menisektomi ihtiyacı doğmuş ve kalan hastalarda bu süre sonunda ortalama 87,3'lük Lysholm skoru elde edilmiştir. ${ }^{[18]}$ İçtendışa teknikte kullanılan dikiş modellerini inceleyen mekanik çalışmalarda vertikal matris dikişlerin horizontal dikişlerden daha güçlü tespit sağladığı gösterilse de ${ }^{[19]}$, Aros ve ark. yakın zamanda yaptıkları çalışmalarında, kuvetlendirilmiş iplerin kullanılması ile, dikiş oryantasyonundan bağımsız olarak yetmezlik oranlarının aynı olduğunu bulmuşlardır. ${ }^{[20]}$ iç̧ten-dışa tekniği, genel anlamda radyal yırtıklarda horizontal planda tek bir dikiş hattına olanak tanımaktadır. Yapılan biyomekanik çalışmalarda, radyal yırtıklarda, basit tek hatlı içten-dışa tekniği ile yapılan tamirin, kompleks dikiş konfigürasyonunun uygulanabildiği çoklu dikiş atılabilen güncel tamamı içeride tamir yapılarına göre, yüklenme kuwetlerine daha az dayanıklı olduğu gösterilmiştir. ${ }^{[21]}$ Yakın zamanda yapılmış kapsamlı bir meta-analizde, içtendışa tekniğinde klinik başarısızıı oranı, tamamı içeride tekniği ile benzer şekilde, sırasıyla $\% 11$ ve $\% 10$ olarak bulunmuştur. ${ }^{[22]}$

Menisküs tamirleri, klinik veya anatomik olarak değerlendirilebilir. Genel olarak kabul edilen görüş, klinik başarı oranının, anatomik iyileşme oranına göre daha yüksek olduğudur. Başka bir deyişle, anatomik olarak iyileşme sağlanmasa bile, bazı yırtıklar klinik bulgu vermeyebilir. Bu nedenle, sadece klinik değerlendirme yapılan serilerin sonuçları, ikincil artroskopi veya MR-artrografi yapılan serilere göre daha iyi bulunur. Menisküs tamiri sonrası başarısızlık genellikle iki yıl civarında ortaya çıkar. Bu nedenle, iki yıldan az izlemi olan serilerin sonuçları dikkatle değerlendirilmelidir. Menisküs onarımının değerlendirilmesinde standart manyetik rezonans (MR) görüntüleme kullanımı ile yanıltıcı sonuçlar elde edilebilir. Kova sapı ve ayrılmış rerüptürler standart MR ile saptanabilir. Ancak, menisküs onarımı iyileşse bile, MR'de tamir bölgesindeki fibrovasküler skar dokusu, yüksek sinyal yoğunluğu sebebiyle yırtık olarak değerlendirilebilir (Şekil 1). Miao ve ark., yırtık iyileşse bile, standart MR görüntülemesinde olguların \%50'sinde anormal sinyal yoğunluğunun 12 yıla kadar devam edebildiğini göstermişlerdir. ${ }^{[23]}$

Bu nedenle, menisküs onarımının değerlendirilmesinde MR-artrografi veya ikincil artroskopi kullanımı daha doğru sonuç verecektir. Menisküs onarımının değerlendirilmesinde Henning kriterleri kullanılır. ${ }^{24]}$ Tamir bölgesinde \%10'dan daha az bir yarık varsa, menisküs iyileşmiş kabul edilir. Yüzde 50 yarık varsa kısmi iyileşme, daha fazla yarık varsa başarısızıık olarak kabul edilir (Şekil 2). Klinik başarısızlık; geçmeyen mekanik semptomlar, effüzyon ve eklem çizgisi hassasiyeti olarak tanımlanmıştır. Aynı metaanalizde, anatomik yetmezlik tespiti için MR görüntüleme, artrogram ve ikincil bakı artroskopi kriter olarak alınmış ve tamir edilmiş menisküsteki kısmi iyileşme veya tam ayrılma varlığı başarısızlık olarak kabul edilmiştir. Bu anatomik yetmezlik, içten-dışa ve tamamı içeride tekniklerde sırasıyla $\% 13$ ve \%16 

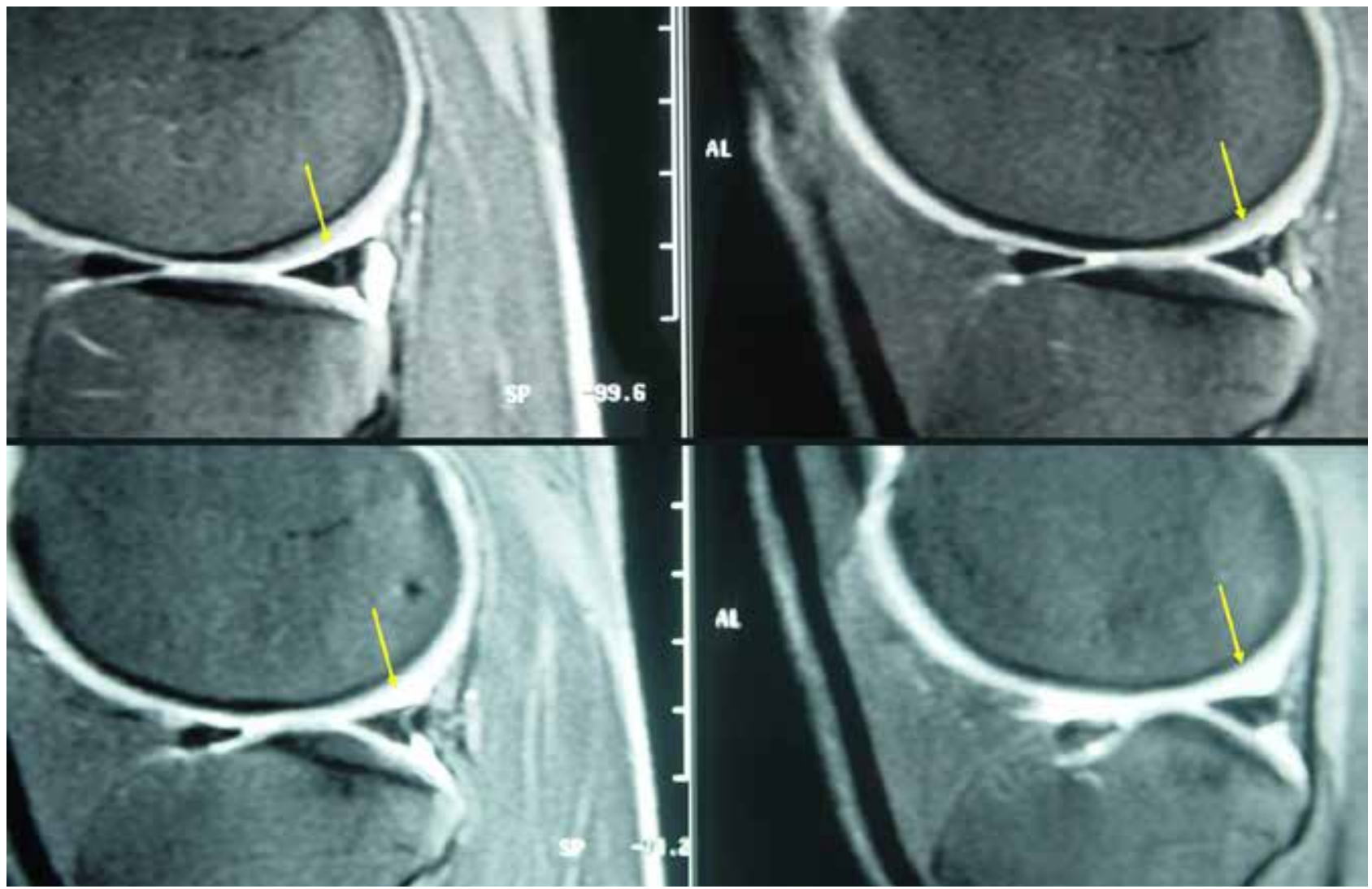

Şekil 1. Mediyal menisküs tamirinden 38 ay sonraki standart MR görüntüler. Menisküste iyileşme sağlanmış olmasına rağmen onarım bölgesinde anormal sinyal yoğunluğu devam ediyor (sarı oklar). Hasta profesyonel futbola asemptomatik olarak devam ediyor.

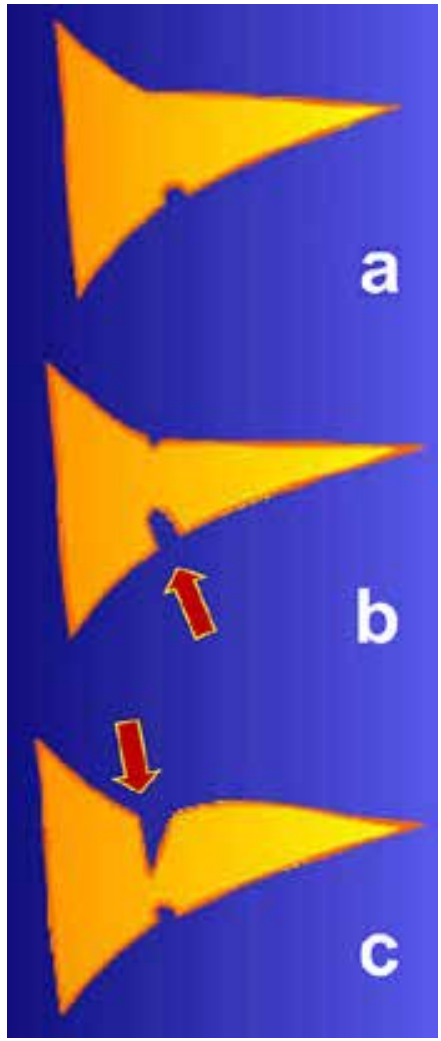

Şekil 2. a-c. Menisküs iyileşmesinin anatomik değerlendirilmesinde Henning kriterleri. İyileşmiş: \%10'dan az yarık (a). Kısmi iyileşme: \%50'den az yarık (b). Başarısız: \%50'den fazla yarık (c). olarak tespit edilmiş̧tir. Klinik skorlar incelendiğinde ise, meta-analize dahil edilen 150 çalışmanın hepsi göz önüne alındığında, 1224 yırtık tamirinin (676 içten-dışa, 548 tamamı içeride tamir) ortalama 57 aylık takibinde Lysholm skoru 89,0 $\pm 3,8$ olarak elde edilmiştir. İçten-dışa özelinde bu skor $88,0 \pm 3,5$ iken, tamamı içeride teknikte $90,4 \pm 3,7$ olarak benzer şekilde bulunmuş̧ur (Tablo 1). ${ }^{[22]}$

\section{Tamamı İçeride Teknik Tamir Sonuçları}

Tamamı içeride tamir tekniği, cerrahi süreyi kısaltmak, ipliklerin bağlanması için gerekli yaklaşımlardan doğabilecek komplikasyonları ortadan kaldırmak ve arka kök yırtıklarına güvenli ulaşabilmek için geliştirilmiştir. ${ }^{[25]} \mathrm{Bu}$ teknik için birinci nesil cihazlar olarak kabul edilebilecek ilk tanımlamayı Morgan 1996'da yapmış ve aksesuvar posterior portal kullanarak eğimli dikiş kancalarının arka boynuz yırtıklarında kullanımını tarif etmiştir. ${ }^{[26]}$ Bunun için, posterior portalden kanca şeklindeki sütür taşıyıcı ile menisküs arka boynuzdaki yırtığa yerleştirilen dikiş, yine bu posterior portal üzerinden dügüümlenerek, açık insizyon yapılmadan yerleştirilmiş olmaktaydı. 
Tablo 1. Literatürde içten dışa onarım tekniği klinik ve anatomik başarısızlık sonuçları ${ }^{[22]}$

\begin{tabular}{lccc}
\hline Yazar (yıl) & Toplam yırtık sayısı (izole) & Klinik başarısızlık sayısı (\%) & Anatomik başarısızlık sayısı (\%) \\
\hline Johannsen (1988) & $17(10)$ & $0(0)$ & - \\
Cannon (1992) & $90(22)$ & $8(9)$ & $16(18)$ \\
Albrecht-Olsen (1993) & $27(27)$ & $10(37)$ & - \\
Jensen (1994) & $36(22)$ & $2(9)$ & $5(14)$ \\
Horibe (1996) & $36(36)$ & $4(11)$ & - \\
Perdue (1996) & $45(9)$ & $4(9)$ & $8(24)$ \\
Albrecht-Olsen (1999) & $34(15)$ & $4(12)$ & - \\
Steenbrugge (2004) & $20(13)$ & $0(0)$ & - \\
Raza (2011) & $15(15)$ & $3(20)$ & - \\
Tengrootenhuysen (2011) & $54(15)$ & $11(20)$ & - \\
Haklar (2013) & $112(23)$ & $13(12)$ & $7(29)$ \\
Espejo-Reina (2014) & $24(7)$ & $4(17)$ & $8(5)$ \\
Steadman (2015) & $148(88)$ & $81(5)$ & $44(13)^{*}$ \\
Toplam & $658(302)$ & & \\
\hline
\end{tabular}

*Ortalama frekans ağırlıklı başarııızlık oranı.

İkinci ve üçüncü nesil tamamı içeride tekniklerde, emilebilir polimerden yapılmış sert oklar veya vidalar menisküse yerleştirilir. Bunlar, esnek olmayan materyaller oldukları için, esnek olan menisküs yapısı içerisinde rijid bir tespite neden olmakta ve kırılmaya maruz kalmaktaydı. ${ }^{[27]}$ Yine, bu materyallerin uygulanması ile kondral hasarın oluştuğu da literatüre girmiştir. ${ }^{[28]} \mathrm{Bu}$ komplikasyonların gelişmesi üzerine, bu implantların benzeri başsız vida ve oklar üçüncü nesil olarak endüstri tarafindan sunulmuştur. Bu iyileştirilmiş rijid implantlar günümüzde halen kullanılıyor olmakla birlikte, sütür onarımlardan mekanik olarak daha zayıftırlar. ${ }^{[29]}$ Järvelä ve ark., menisküs vidaları ve okları ile tamir ettikleri 42 menisküs yırtığını ortalama iki yıl boyunca takip etmişler, hastaların 11'inde MR veya ikincil artroskopik bakı sonucuna göre menisektomi uygulamışlardır. ${ }^{[30]}$ Bu seride, başarısızlık oranı meniskal ok grubunda daha fazla bulunmuştur. Yine hastaların altısında kondral hasar tespit edilmiş ve bu hastaların hepsi de menisküs okları grubunda saptanmıştır. Klinik skorlar açısından iki implant arasında farklılık bulunamamıştır. İkinci ve üçüncü nesil tamamı içeride menisküs tamir cihazlarının diğer komplikasyonları arasında; inflamatuvar reaksiyon, geçici sinovit, kist formasyonu ve cihaz yetmezliği, kırılması veya yer değiştirmesi sayılabilir. ${ }^{[31]}$ Bu nesil cihazların en önemli eksikliklerinden birisi de, uygulandığında yırtık hattındaki gerilme ve kompresyon miktarının ayarlanmasına izin vermemeleri idi. Yetersiz başarı oranları, fazla komplikasyon sayıları ve ayarlanabilir olmamaları, dördüncü nesil cihazların geliştirilmesine yol açmıştır.
Dördüncü nesil cihazlar; esnek, gerilme ve kompresyon miktarı ayarlanabilir, dikiş temelli cihazlardır. Dikiş temelli olmaları nedeniyle, her biri kendi özellik ve teknik uygulama modeline sahip çok sayıda cihaz geliştirilmiştir. Uygulamalarında tek bir veya çoklu dikiş konfigürasyonuna olanak tanımaları nedeniyle, her bir cihazın uygulamasında yırtık tipi önem arz eder. Yine, tespit materyallerinin yerleştirilmesinde aktif veya pasif tetik mekanizmalarına sahip olmalarına göre de farklılıklar gösterirler. Bu cihazların üzerindeki ölçülü kılıflar, uygulanacak tamir cihazının yerleştirilme derinliğinin ayarlanmasına izin verir ve olası nörovasküler yaralanmaların önlenmesine olanak tanır. Yapılan çalışmalarda, 13 mm'lik bir derinliğin implant yerleşimi için güvenli ve yeterli olduğu gösterilmiştir. ${ }^{[32]}$ Dördüncü nesil cihazlar, öncekilerinin aksine klinik ve mekanik olarak daha etkili sonuçlar vermiştir. ${ }^{[25]}$ Güneş ve ark., bu tamir cihazlarının primer tespit güçlerinin dıştan-içe implantlar kadar güçlü olduğunu göstermişlerdir. ${ }^{[33]}$ Rosso ve ark. ise, bu cihazların döngüsel yüklenme (cyclic loading) sağlamlığını içten-dışa dikiş sistemleri ile karşılaştırmış ve benzer sonuçlar elde etmişlerdir. ${ }^{[34]}$ Tamamı içeride menisküs tamir cihazlarının klinik sonuçlarına bakıldığında, Pujol ve ark., ortalama 10 yıllık sonuçlarını yayımlamışlardır. ${ }^{[35]}$ Cerrahi sırasında 22 yaş ortalamasına sahip hastalarında, takip süresinin sonunda International Knee Documentation Committee (IKDC) skorlarını olguların \%92'sinde iyi olarak bulmuşlar, 41 olgunun 23 'ünde, normal dizle karşılaştırıldığında 
menisküsü onarılmış dizlerde hiçbir osteoartrit bulgusuna rastlamazken, altı dizde Evre 1 ve bir dizde Evre 2 osteoartrit bulguları gözlemlemişlerdir. Tüm hastaların içinde menisektomiye giden hasta oranı yaklaşık \%13 bulunmuştur. Horizontal yırtık tipinde, tamamı içeride cihaz kullanılarak değişik konfigürasyonlarda dikiş yerleştirilmesi yırtık tespiti ve iyileştirmesini arttırmaktadır. Tiftikçi ve ark., ortalama 29 aylık takiplerinde tamamı içeride cihazla, overlok (overlock) yöntemi kullanarak tamir ettikleri horizontal menisküs yırtıklarında klinik sonuçlarda belirgin iyileşme göstermişlerdir. ${ }^{[36]}$ Bu sonuçlar, tamamı içeride tamir yönteminin, literatürde yer alan tüm menisküs tamiri yöntemlerinin uzun dönem sonuçları ile uyumlu olduğunu göstermektedir.

\section{İzole Longitudinal ve Kova Sapı Menisküs Yırtıklarının Tamir Sonuçları}

Menisküs onarımını içeren çalışmaların çoğu, longitudinal ve kova sapı yırtıklar içermektedir. Menisektomi ve onarımın sonuçlarını karşılaştıran çalışmalarda klinik açıdan menisküsün korunmasının daha üstün olduğu gösterilmiştir. ${ }^{[37-39]}$ Ikeuchi, ilk artroskopik menisküs dikiş tamirini uygulamıştır. ${ }^{[0]}$ Henning ve ark., artroskopik teknikle periferal menisküs onarımının mümkün olduğunu ilk bildiren yazarlardandır. ${ }^{[24]}$ Literatürde, menisküs onarımının sonuçlarını ikinci bakış artroskopi ile değerlendiren çalışmalarda başarı oranları \%82,1 ile \%96,4 arasında bildirilmiştir. ${ }^{[41,42]}$ De Haven ve ark., kapsülden 2 mm'ye kadar olan yırtıkları tamir etmişler ve $\% 85$ başarı bildirmişlerdir. Başarısız oldukları olgular, instabil dizlerdir. ${ }^{[43]}$ Özellikle izole lezyonlarda daha iyi sonuçlar elde edildiği bildirilmiştir. ${ }^{[44]}$ Ancak \%10-20 hastada hala başarısız sonuçlar bildirilmektedir. ${ }^{[45]}$ Yırtık boyutunun sonuçları etkilemediği bildirilmesine rağmen, özellikle $40 \mathrm{~mm}$ den büyük kova sapı yırtıkların tamir sonuçlarının kötü olduğu bildirilmiştir. ${ }^{[46]}$ Tengrootenhuysen ve ark., yaralanmadan sonra altı hafta içinde uygulanan tamir sonuçlarının geç tamirlere göre daha iyi olduğunu bildirmişlerdir. ${ }^{[47]}$ Genç hastalarda rehabilitasyon programına uyumsuzluk ve ileri yaştaki hastalarda doku kalitesinin kötü olması nedeniyle sonuçların daha kötü olduğu bildirilmiştir. ${ }^{[11]}$ Rubman ve Noyes, ikincil artroskopik incelemeyi içeren çalışmaları değerlendirdikleri derlemede, $\% 25$ olgunun tam iyileştiği, \%38 parsiyel iyileşme ve $\% 36$ hastada ise başarısızlık olduğunu ${ }^{[48]}$, Eggli ve ark. ise menisküs periferinden $3 \mathrm{~mm}$ 'ye kadar olan yırtıkların prognozunun daha iyi olduğunu bildirmişlerdir. Ayrıca, akut ve küçük yırtıkların sonuçları daha iyi olarak belirtilmektedir. ${ }^{[49]}$

Pujol ve ark., 27 menisküs tamirinin uzun dönem (ort. 114 ay) sonuçlarını incelemişler ve klinik sonuçların erken dönem kadar iyi olduğunu bildirmişlerdir. ${ }^{[35]}$
Birçok çalışmada benzer sonuçlar elde edilmiştir. ${ }^{[37,50]}$ En az beş yıllık, ortalama 7,4 yıllık takip süreli, 566 dizi inceleyen bir sistematik derlemede toplam klinik başarısızık oranını \%23 olarak bildirilmiştir. ${ }^{[45]}$ Paxton ve ark., menisküs onarımı ve parsiyel menisektominin uzun dönem radyolojik sonuçlarını karşılaştırmışlar, onarım yapılanların \%78'inde ve menisektomi yapılanarın ise \%64'ünde dejeneratif değişiklikler olmadığını bulmuşlardır. ${ }^{[38]}$ Yani, onarım yapılanlarda daha az radyolojik dejenerasyon tespit etmişlerdir. Rockborn ve ark., 13 yıllık takip süresine sahip çalışmalarında, menisküs onarımı yapılan hastaların \%80'inde normal diz fonksiyonu elde etmişlerdir. ${ }^{[51]}$

\section{Ön Çapraz Bağ Yaralanmalarına Eşlik Eden Yırtıkların Tamir Sonuçları}

Menisküslerin birincil görevi dizde yük taşınması ve aktarılmasıdır; ancak özellikle mediyal menisküs arka boynuzu dizin ön-arka stabilitesine de ikincil olarak katkıda bulunur. Birçok biyomekanik çalışmada, ön çapraz bağ (ÖÇB) olmayan dizlerde yapılan meniskal rezeksiyonun anterior tibial translasyona (ATT) neden olduğu gösterilmiştir. ${ }^{[52,53]}$ Lateral menisküsle ilgili ise çelişkili sonuçlar mevcuttur. ${ }^{[54,55]}$ ÖÇB onarımı yapılan ancak menisküs defekti olan dizlerde, dizin kinematiğinin değişmesi nedeniyle ciddi başarısızlık riski vardır. Bu durumda greft üzerindeki yükler \%55'e kadar artmaktadır. ${ }^{[56]}$ Robb ve ark., iki yıllık takipte menisküs sağlam olan ÖÇB tamirlerinin sağkalımını \%94,5, menisküs kaybı olan dizlerde ise \%69 olarak tespit etmişler ve başarısızık oranını 4,9 kat fazla bulmuşlardır. Ayrıca, menisküs onarımı yapılan dizlerde bu riskte artış tespit etmemişlerdir. ${ }^{[57]}$ Menisküs tamirinin ÖÇB onarımı ile aynı anda yapılması önerilmektedir. ${ }^{[47]}$ Özellikle ÖÇB onarımı için açılan tünellerden eklem içine geçen kanlı sıvıda, menisküs iyileşmesini olumlu etkileyecek birçok faktör vardır. ${ }^{[58]}$ Lyman ve ark., 9529 ÖÇB ve menisküs onarımı yapılan hastayı içeren serilerinde, sadece \%8,9 başarısızlık içeren iyi klinik sonuçlar bildirmişlerdir. ${ }^{[59]}$ Wasserstein ve ark. ${ }^{[60]}$, ÖÇB ve menisküs onarımı birlikte yapılan hastalarda \%7 reoperasyon oranı, Westermann ve ark. ise altı yıllık takipte \%14 başarısızlık tespit etmişlerdir. ${ }^{[52]}$ Bogunovic ve ark., izole ve ÖÇB ile birlikte yapılan menisküs onarımlarının başarısızlıkları arasında fark bulamamışlardır. ${ }^{[61]}$ Rochcongar ve ark., özellikle ÖÇB tamiri sonrası kalan laksitenin menisküs onarımında başarısızlık riskini arttırdığını tespit etmişlerdir. ${ }^{[62]}$ Uzun ve ark., menisküs onarımı yapılan ve ÖÇB tamiri eşlik eden ve etmeyen hastaların sonuçlarını karşılaştırmış ve iki grup arasında başarısızlık ve yırtık tipi açısından fark bulamamışlardır. ${ }^{[63]}$ Ayrıca, ÖÇB olmayan dizlerde yapılan menisküs onarımının başarısızlık oranları artmaktadır. ${ }^{[64]}$ 

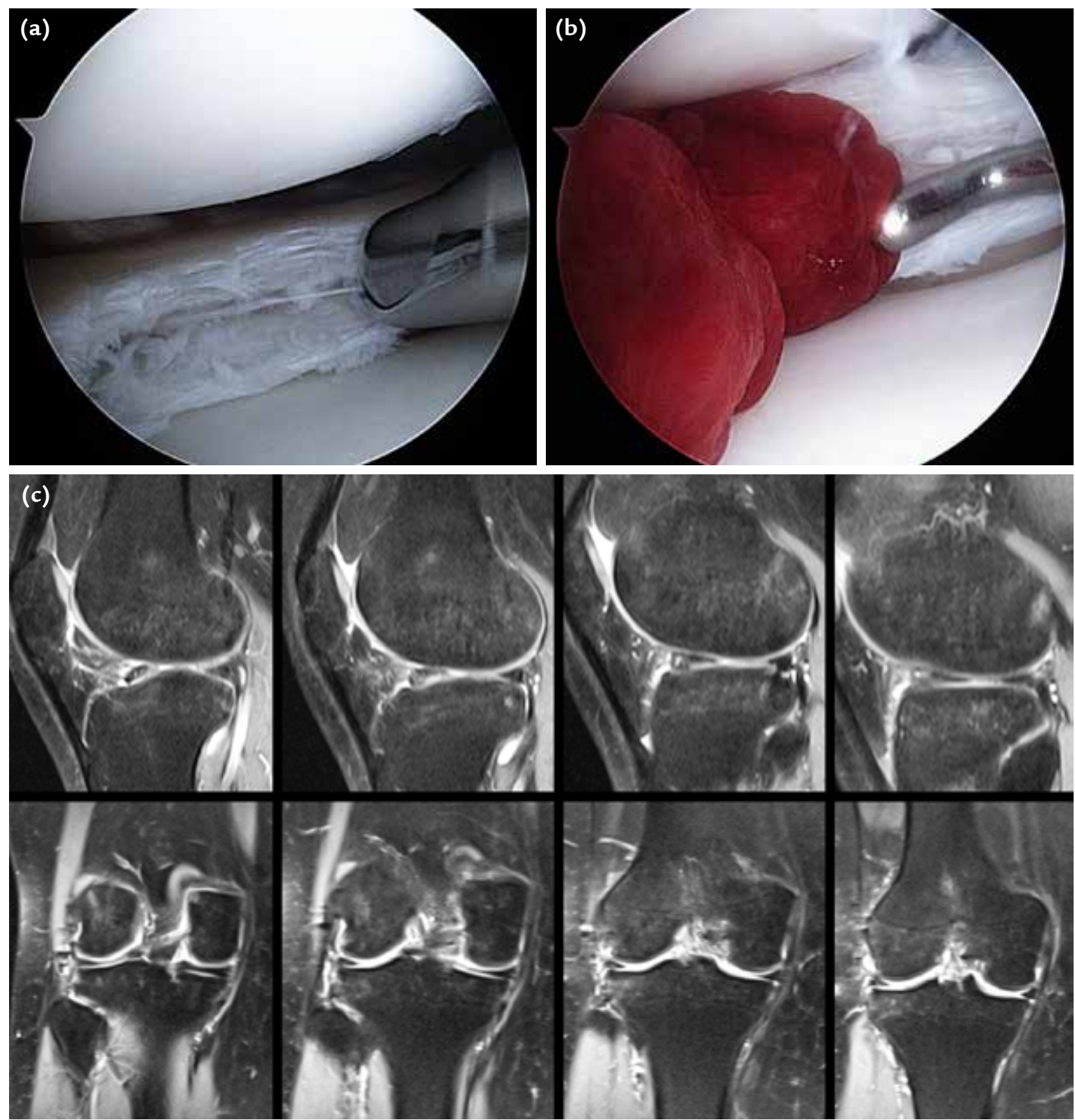

Şekil 3. a-c. Lateral menisküste horizontal klivaj yırtığı olan 15 yaşında kız çocuğunda menisküs onarımı. Yırtığın artroskopik görüntüsü (a). Onarım sırasında fibrin pıhtısı kullanılarak iyileşme arttırılmış (b). İki yıl sonraki MR görüntülerde tam iyileşme sağlanmış (c).

\section{Horizontal Klivaj Yırtıkları Tamir Sonuçları}

Horizontal klivaj yırtıkları, menisküsün santralinden başlayarak intrameniskal olarak ilerleyip menisküsü alt ve üst iki laminaya ayıran yırtıklardır. ${ }^{[65]}$ Özellikle dejeneratif ve ileri yaşlarda görülmesine karşın, gençlerde de karşılaşılabilmektedir. Bu yırtıklar genelde parsiyel menisektomi ile tedavi edilir ve genelde potansiyel sütür yetmezliği, düşük iyileşme kapasiteleri ve genelde avasküler zona uzandıkları için tamir edilmezler. ${ }^{[66,67]}$
Ancak, bu olumsuz yaygın kanıya ve birçok yayında horizontal yırtık tanısı çalışmadan çıkarılma kriterlerine konmasına rağmen; geniş serileri inceleyen sistematik bir derlemede tamir başarı oranı \%77,8 olarak bildirilmiş ve diğer yırtıklarla karşılaştırılabilecek bir başarı oranı olarak yorumlanmıştır. Genç hastalarda görülen horizontal yırtıklarda tamir denenmelidir. Yırtık tazelendikten sonra, fibrin pıhtısı gibi iyileşmeyi arttırıcı yöntemler ile dikiş tamir yapılmalıdır (Şekil 3). ${ }^{68]}$ 
Horizontal yırtıklara bazen menisküs kistleri eşlik edebilir. Kist tedavisi artroskopik ve açık yöntemlerle yapılabilir. Pujol ve ark., açık menisküs onarımı ve kist eksizyonu yaptıkları 15 menisküs kistinde ortalama 40 aylık takipte nüks tespit etmemişlerdir. ${ }^{[69]}$ Ryu ve Ting, 18 kistin artroskopik tedavisinde yedi yıllık takipte nüks saptamamışlardır. ${ }^{[70]}$ Ancak üç hastada kisti çıkarmak için subtotal menisektomiye ihtiyaç olduğunu bildirmişlerdir. Hulet ve ark., artroskopik tedavi ettikleri 105 lateral menisküs kistini ortalama 5 yıl takip etmişler ve $\% 87$ hastada iyi ve mükemmel klinik sonuç elde etmişlerdir. Kist dekompresyonu sonucu dıştan içe teknikle vertikal menisküs sütür onarımı ile iyi sonuçlar bildirilmiştir. ${ }^{[71]}$

\section{Menisküs Kök Lezyonları Tamir Sonuçları}

Lateral ve mediyal menisküs kökleri anterior ve posteriorda tibial platoya tutunmaktadır. Posterior kök yaralanmaları akut veya dejeneratif nedenlerle olabilir. Genel olarak, mediyal menisküs arka kök yırtıkları orta-ileri yaştaki hastalarda ve dejeneratif kökenliyken, lateral menisküs arka kök yırtıkları genç hastalarda görülür ve sıklıkla ön çapraz bağ yaralanmalarına eşlik eder. Bir çalışmada mediyal menisküs yırtıklarının \%21,5'inin kök yırtığı olduğu bildirilmiştir. ${ }^{[72]}$ Mediyal menisküs arka kök yırtıkları, genellikle dizdeki dejeneratif sürecin bir parçasıdır. Hastalar, basit bir travma sonrası diz arkasında ağrı ve sonrasında giderek artan yakınmalar tarif ederler. Kök yırtığı sonrası menisküsün çevresel (circumferential) liflerinin devamlılı̆̆ı bozulduğu için, yük taşıma işlevi etkisiz hale gelir. Menisküs yük altında eklem dışına itilir, buna meniskal taşma (extrusion) adı verilir. Tibia platosuna binen yüklerin artması nedeniyle, kök yırtıklarına ağrılı kemik iliği ödemi de eşlik edebilir. Mediyal menisküsün $<3 \mathrm{~mm}$ platodan taşmasının artmış kıkırdak hasarı ve osteofit oluşumu ile ilişkisi gösterilmiştir. ${ }^{[73]}$ Bu nedenle posterior meniskal kök yaralanmalarında amaç, menisküs kökünün tekrar kemiğe iyileşmesini sağlayarak çevresel liflerin devamlılığını yeniden oluşturmak, mümkünse meniskal taşmayı düzeltmek ve dejeneratif süreci durdurmaktır. ${ }^{[74]}$ Genelde aktif, $<50$ yaş, tam kat kıkırdak hasarı olmayan, eklem aralığı korunmuş ve dizilim bozukluğu olmayan hastalarda tamir endikasyonu vardır. ${ }^{[75,76]}$ Eğer eşlik eden varus dizilim bozukluğu varsa, proksimal tibial osteotomi ile düzeltilmelidir, zira varus dizilimi olan bir dizde kök yırtığı onarımının başarılı olması beklenmez (Şekil 4). Son yıllarda 'transtibial pullout' ve sütür ankor tekniği gibi tamir yöntemlerinde ciddi gelişmeler olmuştur.

Klinik çalışmalarda[76-79], mediyal menisküs posterior kök tamirinde subjektif sonuçlarda özellikle 2-3 yıllık takiplerde önemli gelişmeler bildirilmiş olmasına rağmen, MR ve ikinci bakış artroskopi ile yapısal sonuç bildiren çalışmalarda çelişkili bulgular elde edilmiştir. Kim ve ark. ${ }^{[80]}$ tamir sonrası meniskal taşmanın azaldığını, Jung ${ }^{[78]}$ ise değişmediğini ve Moon ve ark. ${ }^{[77]}$ ise tersine taşmanın arttığını bildirmişlerdir. Ancak, bu çaIışmalardaki olumsuz sonuçlar ileri yaş ve osteoartrit derecesine sahip hastaların olabilir. Lee ve ark., 'transtibial pullout' yöntemle tedavi ettikleri 10 hastanın ikincil artroskopik değerlendirmesinde, hastaların tümünde iki yılda iyileşme olduğunu bildirmişlerdir. ${ }^{[79]}$ Seo ve ark., ikincil artroskopik değerlendirme ile 11 hastanın bir yılda hiçbirinde iyileşme tespit edememişler ve bunların çoğunun kronik yırtık olduğunu bildirmişlerdir. ${ }^{[75]}$ Tamir tekniği sonuçları etkileyebilir. 'Transtibial pullout' teknikte, açılan tünelden ekleme geçen progenitor hücrelerin iyileşmeyi arttırdığı bildirilmiştir. ${ }^{[81]}$ Ancak bu teknikte görülen 'bungee effect' tamir sahasında mikro harekete neden olarak iyileşmeyi olumsuz etkileyebilir. ${ }^{[82]} \mathrm{Bu}$ hareketin sütür ankor ile yapılan tamirlerde daha az görüldüğü bildirilmiştir. ${ }^{[78]}$

Buna karşın, lateral menisküs arka kök yırtıkları travmatiktir ve sıklıkla akut ön çapraz bağ yırtığına eşlik eder. Bir seride, ÖÇB yaralanmalarının \%8'inde posterolateral menisküs kök lezyonu olduğu gösterilmiştir. [73] Lateral menisküs kök yırtığının onarımı, ÖÇB cerrahisinin başarılı olması ve grefte binen anormal yüklerin azaltılması açısından büyük önem taşır. ${ }^{[83]}$ Tanısında özellikle MR koronal kesitleri değerlidir, ancak duyarlılığı yüksek değildir. Bu hastalarda özellikle pivot-shift derecesinde anlamlı olarak artış tespit edilmiştir. ${ }^{[84]}$ Literatürde, tamir edilmeyen bu kök yırtıklarında kalan instabilitenin klinik sonuçları kötüleştirdiği ve osteoartrite gidişi hızlandırdığı bildirilmiştir. ${ }^{[85]}$ Özellikle ÖÇB tamiri esnasında iyi bir tanısal artroskopik değerlendirme ve kök tamiri için hazırlıklı olunması gerektiği vurgulanmaktadır. ${ }^{[83]}$

\section{Menisküs Ramp Lezyonu Tamir Sonuçları}

Menisküs "ramp" lezyonu; mediyal menisküsün arka boynuzunun menisko-tibial ligamentteki hasar sonucu kapsüle yapıştığı yerde olan yırtıklarıdır. Genellikle longitudinal ve $2,5 \mathrm{~cm}$ 'den azdır ve ÖÇB yaralanmalarının \%9-17'sinde görüldüğü bildirilmiştir. ${ }^{[86]}$ Tanısında, MR düşük duyarlılığa sahiptir.[87] Tanı için sistematik bir artroskopik değerlendirme gereklidir. ${ }^{[88]}$ Tamirinde içten-dışa ve tamamı içerde teknikler kullanılabilir. Ahn ve ark., postero-mediyal portal yardımıyla tamir ettikleri vakalarda iyi iyileşme oranları elde etkilerini bildirmişlerdir. ${ }^{[41]}$ Liu ve ark., 23 hastanın tamamı içeride teknikle tamirinin, ortalama 14 aylık takipli klinik sonuçlarında anlamlı düzelme saptamışlardır. ${ }^{[86]}$ Güncel bir kadavra çalışmasında, tamamı içeride teknikle biyomekanik olarak 

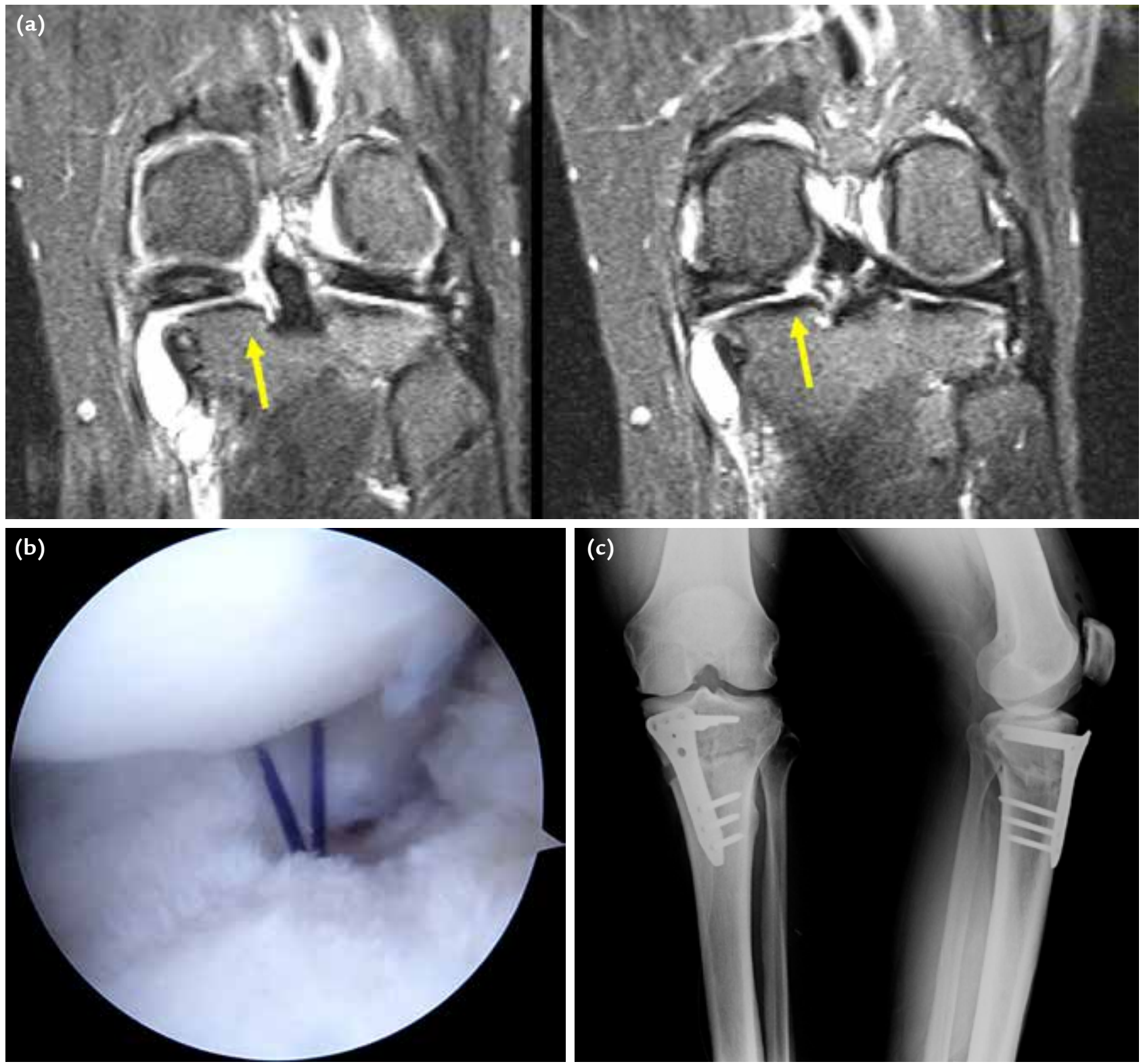

Şekil 4. a-c. Varus dizilimi ve mediyal menisküs kök yırtığı olan 44 yaşında erkek hastada kök onarımı ile birlikte proksimal tibial osteotomi uygulaması. Ameliyat öncesi koronal MR kesitlerde kök yırtığı (a). Artroskopik trans-tibial kök onarımı görüntüsü (b). Ameliyat sonrası grafilerde dizilim düzeltilmiş, menisküs onarımı dikişleri tibial plak delikleri üzerinde bağlanmış (c).

düşük başarısızlık oranları bildirilmiştir. ${ }^{[89] ~ " R a m p " ~}$ lezyonunun tamamı içeride teknikle tamirinin ikincil artroskopi ile değerlendiren bir çalışmada \%87 başarı bildirilmiştir. Özellikle menisküs tamir sistemlerinin gelişmesi ile hızlı ve güvenilir şekilde iyi sonuçlar elde edilebileceği bildirilmektedir. ${ }^{[89]}$

\section{Radyal Menisküs Yırtıkları Tamir Sonuçları}

Menisküsün çevresel yerleşimli lifleri, menisküs yapısının bütünlüğüne önemli katkıda bulunmaktadır. ${ }^{[90]}$
Radyal menisküs yırtıkları bu lifleri dik olarak keserek, yük dağılımını biyomekanik olarak longitudinal yırtıklardan daha fazla bozar. ${ }^{[91]}$ Mediyal menisküs arka boynuzunun radyal yırtıkları, tüm menisküs yırtıklarının \%28'ini oluşturur. ${ }^{[92]} \mathrm{Bu}$ yırtıkların tedavisinde, mekanik semptomları azaltmak ve kalan menisküsü korumak amacıyla çoğunlukla parsiyel menisektomi uygulanmaktadır. ${ }^{[93]}$ Ancak, menisektominin dejeneratif değişiklere yol açtığı bildirilmiştir. ${ }^{[94]}$ Son yıllarda, menisektomiye alternatif, uzun dönemde dejeneratif 
değişikleri önlemek ve klinik sonuçları iyileştirmek için tamir teknikleri gelişmiştir. ${ }^{[95]}$ Altı çalışmayı içeren güncel bir sistematik derlemede, ortalama 38,4 ayda hastalarda klinik sonuçlarda anlamlı düzelme bildirilmiştir. Aynı çalışmada parsiyel menisektomi sonrası gelişen osteoartritin 10 yıl üzerinde görülebileceği, bu nedenle tamir ile yapılacak karşılaştırmalarda uzun takip sürelerine ihtiyaç olduğu vurgulanmıştır. ${ }^{[96]}$

Menisküsün gövdesinde olan radyal yırtıklarda iyileşme sağlansa bile, çevresel liflerin devamlılığı bozulduğu için menisküs işlevlerinin tam olarak gerçekleşmeyeceği düşünülmekteydi. Ancak, 20 yaşın altındaki hastaların travmatik radyal menisküs yırtıklarında, özellikle lateral menisküs yırtıklarında onarım denenmelidir. Bu hastalarda iyileşmeyi arttırıcı yöntemler kullanılmalı, sağlam tespit yapılmalı ve yükten kurtarma süresi iki aya kadar uzatılmalıdır.

\section{SONUÇ}

Sonuç olarak; menisküs yırtıklarının uygun endikasyonda yapılan tamirlerinin sonuçları literatürde başarılı olarak bildirilmektedir. Genç ve aktif bireylerde tamir endikasyonları genişletilmeli ve menisküsü korumak için bütün çabalar gösterilmelidir. Artroskopik cerrahi ile ilgilenen hekimlerin, menisküs tamir tekniklerini bilmesi ve her ameliyata tamir yapabilecek hazırıkla girmeleri büyük önem taşır.

\section{KAYNAKLAR}

1. Annandale T. An Operation for Displaced Semilunar Cartilage. Br Med J 1885;1(1268):779. Crossref

2. Henning CE, Lynch MA, Clark JR. Vascularity for healing of meniscus repairs. Arthroscopy 1987:3(1):13-8. Crossref

3. Matthews P, St-Pierre DM. Recovery of muscle strength following arthroscopic meniscectomy. J Orthop Sports Phys Ther 1996;23(1):18-26. Crossref

4. Herrlin S, Hållander M, Wange P, Weidenhielm L, Werner S. Arthroscopic or conservative treatment of degenerative medial meniscal tears: a prospective randomised trial. Knee Surg Sports Traumatol Arthrosc 2007;15(4):393-401. Crossref

5. Almqvist KF, Vansintjan P, Verdonk P, Verdonk R. Traumatic Meniscal Lesions in a Stable Knee: Masterly Neglect, Meniscectomy, Repair. In: Beaufils P, Verdonk R, editors. The Meniscus. Berlin Heidelberg: Springer-Verlag; 2010. p.209-14.

6. DeHaven KE, Bronstein RD. Arthroscopic medial meniscal repair in the athlete. Clin Sports Med 1997;16(1):69-86. Crossref

7. Pujol N, Beaufils P. Healing results of meniscal tears left in situ during anterior cruciate ligament reconstruction: a review of clinical studies. Knee Surg Sports Traumatol Arthrosc 2009;17(4):396-401. Crossref

8. DeHaven KE. Decision-making factors in the treatment of meniscus lesions. Clin Orthop Relat Res 1990:(252):49-54. Crossref
9. van Trommel MF, Simonian PT, Potter HG, Wickiewicz TL. Arthroscopic meniscal repair with fibrin clot of complete radial tears of the lateral meniscus in the avascular zone. Arthroscopy 1998;14(4):360-5. Crossref

10. Mordecai SC, Al-Hadithy N, Ware HE, Gupte CM. Treatment of meniscal tears: An evidence based approach. World J Orthop 2014;5(3):233-41. Crossref

11. Cannon WD Jr, Vittori JM. The incidence of healing in arthroscopic meniscal repairs in anterior cruciate ligamentreconstructed knees versus stable knees. Am J Sports Med 1992;20(2):176-81. Crossref

12. Sgaglione NA. The biological treatment of focal articular cartilage lesions in the knee: future trends? Arthroscopy 2003;19 Suppl $1: 154-60$. Crossref

13. Neyret $P$, Donell ST, Dejour D, Dejour H. Partial meniscectomy and anterior cruciate ligament rupture in soccer players. A study with a minimum 20-year followup. Am J Sports Med 1993;21(3):455-60. Crossref

14. Elkousy $H$, Higgins LD. Zone-specific inside-out meniscal repair: Technical limitations of repair of posterior horns of medial and lateral menisci. Am J Orthop (Belle Mead NJ) 2005;34(1):29-34.

15. Lambert EW, Bonner KF. Arthroscopic meniscus repair with sutures: Outside-in. Sports Med Arthrosc Rev 2004;12(1):2536. Crossref

16. Grant JA, Wilde J, Miller BS, Bedi A. Comparison of inside-out and all-inside techniques for the repair of isolated meniscal tears: a systematic review. Am J Sports Med 2012;40(2):45968. Crossref

17. Albrecht-Olsen $P$, Kristensen $G$, Burgaard $P$, Joergensen $\mathrm{U}$, Toerholm C. The arrow versus horizontal suture in arthroscopic meniscus repair. A prospective randomized study with arthroscopic evaluation. Knee Surg Sports Traumatol Arthrosc 1999;7(5):268-73. Crossref

18. Abdelkafy A, Aigner $\mathrm{N}$, Zada M, Elghoul $\mathrm{Y}$, Abdelsadek $\mathrm{H}$, Landsiedl F. Two to nineteen years follow-up of arthroscopic meniscal repair using the outside-in technique: a retrospective study. Arch Orthop Trauma Surg 2007;127(4):245-52. Crossref

19. Rimmer MG, Nawana NS, Keene GC, Pearcy MJ. Failure strengths of different meniscal suturing techniques. Arthroscopy 1995;11(2):146-50. Crossref

20. Aros BC, Pedroza A, Vasileff WK, Litsky AS, Flanigan DC. Mechanical comparison of meniscal repair devices with mattress suture devices in vitro. Knee Surg Sports Traumatol Arthrosc 2010;18(11):1594-8. Crossref

21. Branch EA, Milchteim C, Aspey BS, Liu W, Saliman JD, Anz AW. Biomechanical comparison of arthroscopic repair constructs for radial tears of the meniscus. Am J Sports Med 2015;43(9):2270-6. Crossref

22. Fillingham YA, Riboh JC, Erickson BJ, Bach BR Jr, Yanke AB. Inside-Out Versus All-Inside Repair of Isolated Meniscal Tears: An Updated Systematic Review. Am J Sports Med 2017;45(1):234-42. Crossref

23. Miao Y, Yu JK, Zheng ZZ, Yu CL, Ao YF, Gong X, Wang YJ, Jiang D. MRI signal changes in completely healed meniscus confirmed by second-look arthroscopy after meniscal repair with bioabsorbable arrows. Knee Surg Sports Traumatol Arthrosc 2009;17(6):622-30. Crossref

24. Henning CE, Lynch MA, Yearout KM, Vequist SW, Stallbaumer RJ, Decker KA. Arthroscopic meniscal repair using an exogenous fibrin clot. Clin Orthop Relat Res 1990;(252):6472. Crossref

25. Laible C, Stein DA, Kiridly DN. Meniscal repair. J Am Acad Orthop Surg 2013;21(4):204-13. Crossref 
26. Morgan CD. The "all-inside" meniscal repair. Arthroscopy 1996;7(1):120-5.

27. Calder SJ, Myers PT. Broken arrow: a complication of meniscal repair. Arthroscopy 1999;15(6):651-2. Crossref

28. Kumar A, Malhan K, Roberts SN. Chondral injury from bioabsorbable screws after meniscal repair. Arthroscopy 2001;17(8):34. Crossref

29. Brucker PU, Favre P, Puskas GJ, von Campe A, Meyer DC, Koch PP. Tensile and shear loading stability of all-inside meniscal repairs: an in vitro biomechanical evaluation. Am J Sports Med 2010;38(9):1838-44. Crossref

30. Järvelä S, Sihvonen R, Sirkeoja H, Järvelä T. All-inside meniscal repair with bioabsorbable meniscal screws or with bioabsorbable meniscus arrows: A prospective, randomized clinical study with 2-year results. Am J Sports Med 2010;38(11):2211-7. Crossref

31. Tuman J, Haro MS, Foley S, Diduch D. All-inside meniscal repair devices and techniques. Expert Rev Med Devices 2012;9(2):147-57. Crossref

32. Cohen SB, Anderson MW, Miller MD. Chondral injury after arthroscopic meniscal repair using bioabsorbable Mitek Rapidloc meniscal fixation. Arthroscopy 2003;19(7):E73-5. Crossref

33. Gunes $T$, Bostan B, Erdem M, Asci M, Sen C, Kelestemur $\mathrm{MH}$. Biomechanical evaluation of arthroscopic all-inside meniscus repairs. Knee Surg Sports Traumatol Arthrosc 2009;17(11):1347-53. Crossref

34. Rosso C, Kovtun K, Dow W, McKenzie B, Nazarian A, DeAngelis JP, Ramappa AJ. Comparison of all-inside meniscal repair devices with matched inside-out suture repair. Am J Sports Med 2011;39(12):2634-9. Crossref

35. Pujol N, Tardy N, Boisrenoult P, Beaufils P. Long-term outcomes of all-inside meniscal repair. Knee Surg Sports Traumatol Arthrosc 2015;23(1):219-24. Crossref

36. Tiftikçi U, Serbest S. Repair of isolated horizontal meniscal tears with all-inside suture materials using the overlock method: outcome study with a minimum 2-year follow-up. J Orthop Surg Res 2016;11(1):131. Crossref

37. Melton JT, Murray JR, Karim A, Pandit H, Wandless F, Thomas NP. Meniscal repair in anterior cruciate ligament reconstruction: a long-term outcome study. Knee Surg Sports Traumatol Arthrosc 2011;19(10):1729-34. Crossref

38. Paxton ES, Stock MV, Brophy RH. Meniscal repair versus partial meniscectomy: a systematic review comparing reoperation rates and clinical outcomes. Arthroscopy 2011;27(9):1275-88. Crossref

39. Xu C, Zhao J. A meta-analysis comparing meniscal repair with meniscectomy in the treatment of meniscal tears: the more meniscus, the better outcome? Knee Surg Sports Traumatol Arthrosc 2015;23(1):164-70. Crossref

40. Ikeuchi $\mathrm{H}$. Arthroscopic treatment of the discoid lateral meniscus. Technique and long-term results. Clin Orthop Relat Res 1982;(167):19-28. Crossref

41. Ahn JH, Lee YS, Yoo JC, Chang MJ, Koh KH, Kim MH. Clinical and second-look arthroscopic evaluation of repaired medial meniscus in anterior cruciate ligament-reconstructed knees. Am J Sports Med 2010;38(3):472-7. Crossref

42. Feng $\mathrm{H}$, Hong $\mathrm{L}$, Geng $X S$, Zhang $\mathrm{H}$, Wang XS, Jiang XY. Secondlook arthroscopic evaluation of bucket-handle meniscus tear repairs with anterior cruciate ligament reconstruction: 67 consecutive cases. Arthroscopy 2008;24(12):1358-66. Crossref

43. DeHaven KE, Black KP, Griffiths HJ. Open meniscus repair. Technique and two to nine year results. Am J Sports Med 1989;17(6):788-95. Crossref
44. Greis PE, Holmstrom MC, Bardana DD, Burks RT. Meniscal injury: II. Management. J Am Acad Orthop Surg 2002;10(3):177-87. Crossref

45. Nepple JJ, Dunn WR, Wright RW. Meniscal repair outcomes at greater than five years: a systematic literature review and meta-analysis. J Bone Joint Surg Am 2012;94(24):2222-7. Crossref

46. Henning CE. Arthroscopic repair of meniscus tears. Orthopaedics 1983;6(9):1130-2. Crossref

47. Tengrootenhuysen M, Meermans G, Pittoors K, van Riet R, Victor J. Long-term outcome after meniscal repair. Knee Surg Sports Traumatol Arthrosc 2011;19(2):236-41. Crossref

48. Rubman M, Noyes F, Barber-Westin S. Arthroscopic repair of meniscal tears that extend into the avascular zone. A review of 198 single and complex tears. Am J Sports Med 1998;26(1):87-95. Crossref

49. Eggli S, Wegmüller H, Kosina J, Huckell C, Jakob RP. Longterm results of arthroscopic meniscal repair. An analysis of isolated tears. Am J Sports Med 1995;23(6):715-20. Crossref

50. Lorbach $\mathrm{O}$, Kieb $\mathrm{M}$, Herbort $\mathrm{M}$, Weyers I, Raschke M, Engelhardt $M$. The influence of the medial meniscus in different conditions on anterior tibial translation in the anterior cruciate deficient knee. Int Orthop 2015;39(4):681-7. Crossref

51. Rockborn P, Gillquist J. Results of open meniscus repair. Long-term follow-up study with a matched uninjured control group. J Bone Joint Surg Br 2000;82(4):494-8. Crossref

52. Westermann RW, Wright RW, Spindler KP, Huston LJ; MOON Knee Group, Wolf BR. Meniscal repair with concurrent anterior cruciate ligament reconstruction: operative success and patient outcomes at 6-year follow-up. Am J Sports Med 2014;42(9):2184-92. Crossref

53. Stephen JM, Halewood C, Kittl C, Bollen SR, Williams A, Amis AA. Posteromedial Meniscocapsular Lesions Increase Tibiofemoral Joint Laxity With Anterior Cruciate Ligament Deficiency, and Their Repair Reduces Laxity. Am J Sports Med 2016;44(2):400-8. Crossref

54. Levy IM, Torzilli PA, Gould JD, Warren RF. The effect of lateral meniscectomy on motion of the knee. J Bone Joint Surg Am 1989;71(3):401-6. Crossref

55. Musahl V, Citak M, O'Loughlin PF, Choi D, Bedi A, Pearle $A D$. The effect of medial versus lateral meniscectomy on the stability of the anterior cruciate ligament-deficient knee. Am J Sports Med 2010;38(8):1591-7. Crossref

56. Papageorgiou CD, Gil JE, Kanamori A, Fenwick JA, Woo SL, $\mathrm{Fu} \mathrm{FH}$. The biomechanical interdependence between the anterior cruciate replacement graft and the medial meniscus. Am J Sports Med 2001;29(2):226-31. Crossref

57. Robb C, Kempshall P, Getgood A, Standell H, Sprowson A, Thompson P, Spalding T. Meniscal integrity predicts laxity of anterior cruciate ligament reconstruction. Knee Surg Sports Traumatol Arthrosc 2015;23(12):3683-90. Crossref

58. de Girolamo L, Galliera E, Volpi P, Denti M, Dogliotti G, Quaglia A, Cabitza P, Corsi Romanelli MM, Randelli $P$. Why menisci show higher healing rate when repaired during $\mathrm{ACL}$ reconstruction? Growth factors release can be the explanation. Knee Surg Sports Traumatol Arthrosc 2015;23(1):90-6. Crossref

59. Lyman S, Hidaka C, Valdez AS, Hetsroni I, Pan TJ, Do H, Dunn WR, Marx RG. Risk factors for meniscectomy after meniscal repair. Am J Sports Med 2013;41(12):2772-8. Crossref

60. Wasserstein D, Dwyer T, Gandhi R, Austin PC, Mahomed $\mathrm{N}$, Ogilvie-Harris D. A matched-cohort population study of reoperation after meniscal repair with and without concomitant anterior cruciate ligament reconstruction. Am J Sports Med 2013;41(2):349-55. Crossref 
61. Bogunovic L, Kruse LM, Haas AK, Huston LJ, Wright RW. Outcome of All-Inside Second-Generation Meniscal Repair: Minimum Five-Year Follow-Up. J Bone Joint Surg Am 2014;96(15):1303-7. Crossref

62. Rochcongar G, Cucurulo T, Ameline T, Potel JF, Dalmay F, Pujol N, Sallé de Chou É, Lutz C, Ehkirch FP, Le Henaff G, Laporte C, Seil R, Gunepin FX, Sonnery-Cottet B; la SFA. Meniscal survival rate after anterior cruciate ligament reconstruction. Orthop Traumatol Surg Res 2015;101(8 Suppl):S323-6. Crossref

63. Uzun E, Misir A, Kizkapan TB, Ozcamdalli M, Akkurt S, Guney A. Arthroscopic medial meniscal repair with or without concurrent anterior cruciate ligament reconstruction: A subgroup analysis. Knee 2018;25(1):109-17. Crossref

64. Bach BR Jr, Dennis M, Balin J, Hayden J. Arthroscopic meniscal repair: analysis of treatment failures. J Knee Surg 2005;18(4):278-84. Crossref

65. Verdonk P, Vererfve P. Traumatic lesions: Stable knee, ACL knee. In: Beaufils P, Verdonk R, editors. The Meniscus. New York: Springer; 2010. p.45-50.

66. Boyd KT, Myers PT. Meniscus preservation; rationale, repair techniques and results. Knee 2003;10(1):1-11. Crossref

67. Jouve $F$, Ovadia $H$, Pujol N, Beaufils P. Meniscal repair: Technique. In: Beaufils P, Verdonk R, editors. The Meniscus. New York: Springer; 2010. p.119-28.

68. Kurzweil PR, Lynch NM, Coleman S, Kearney B. Repair of horizontal meniscus tears: a systematic review. Arthroscopy 2014;30(11):1513-9. Crossref

69. Pujol N, Bohu Y, Boisrenoult P, Macdes A, Beaufils P. Clinical outcomes of open meniscal repair of horizontal meniscal tears in young patients. Knee Surg Sports Traumatol Arthrosc 2013;21(7):1530-3. Crossref

70. Ryu RK, Ting AJ. Arthroscopic treatment of meniscal cysts. Arthroscopy 1993;9(5):591-5. Crossref

71. Hulet C, Souquet D, Alexandre P, Locker B, Beguin J, Vielpeau C. Arthroscopic treatment of 105 lateral meniscal cysts with 5-year average follow-up. Arthroscopy 2004;20(8):831-6. Crossref

72. De Smet AA, Blankenbaker DG, Kijowski R, Graf BK, Shinki K. MR diagnosis of posterior root tears of the lateral meniscus using arthroscopy as the reference standard. AJR Am J Roentgenol 2009;192(2):480-6. Crossref

73. Hwang BY, Kim SJ, Lee SW, Lee HE, Lee CK, Hunter DJ, Jung $\mathrm{KA}$. Risk factors for medial meniscus posterior root tear. Am J Sports Med 2012;40(7):1606-10. Crossref

74. Lerer DB, Umans HR, Hu MX, Jones MH. The role of meniscal root pathology and radial meniscal tear in medial meniscal extrusion. Skeletal Radiol 2004;33(10):569-74. Crossref

75. Seo HS, Lee SC, Jung KA. Second-look arthroscopic findings after repairs of posterior root tears of the medial meniscus. Am J Sports Med 2011;39(1):99-107. Crossref

76. Bhatia S, LaPrade CM, Ellman MB, LaPrade RF. Meniscal root tears: significance, diagnosis, and treatment. Am J Sports Med 2014;42(12):3016-30. Crossref

77. Moon HK, Koh YG, Kim YC, Park YS, Jo SB, Kwon SK. Prognostic factors of arthroscopic pull-out repair for a posterior root tear of the medial meniscus. Am J Sports Med 2012;40(5):1138-43. Crossref

78. Jung $\mathrm{YH}$, Choi NH, Oh JS, Victoroff BN. All-inside repair for a root tear of the medial meniscus using a suture anchor. Am J Sports Med 2012;40(6):1406-11. Crossref

79. Lee JH, Lim YJ, Kim KB, Kim KH, Song JH. Arthroscopic pullout suture repair of posterior root tear of the medial meniscus: radiographic and clinical results with a 2-year follow-up. Arthroscopy 2009;25(9):951-8. Crossref
80. Kim JH, Chung JH, Lee DH, LeeYS, Kim JR, Ryu KJ. Arthroscopic suture anchor repair versus pullout suture repair in posterior root tear of the medial meniscus: a prospective comparison study. Arthroscopy 2011;27(12):1644-53. Crossref

81. Feucht MJ, Grande E, Brunhuber J, Rosenstiel N, Burgkart $\mathrm{R}$, Imhoff $\mathrm{AB}$, Braun $\mathrm{S}$. Biomechanical comparison between suture anchor and transtibial pull-out repair for posterior medial meniscus root tears. Am J Sports Med 2014;42(1):187-93. Crossref

82. Stärke C, Kopf S, Gröbel KH, Becker R. The effect of a nonanatomic repair of the meniscal horn attachment on meniscal tension: a biomechanical study. Arthroscopy 2010;26(3):358-65. Crossref

83. Minami $T$, Muneta $T$, Sekiya I, Watanabe $T$, Mochizuki $T$, Horie M, Katagiri H, Otabe K, Ohara T, Katakura M, Koga $\mathrm{H}$. Lateral meniscus posterior root tear contributes to anterolateral rotational instability and meniscus extrusion in anterior cruciate ligament-injured patients. Knee Surg Sports Traumatol Arthrosc 2018;26(4):1174-81. Crossref

84. Song GY, Zhang H, Wang QQ, Zhang J, Li Y, Feng H. Risk Factors Associated With Grade 3 Pivot Shift After Acute Anterior Xcruciate Ligament Injuries. Am J Sports Med 2016;44(2):362-9. Crossref

85. Jonsson $\mathrm{H}$, Riklund-Ahlström $\mathrm{K}$, Lind J. Positive pivot shift after ACL reconstruction predicts later osteoarthrosis: 63 patients followed 5-9 years after surgery. Acta Orthop Scand 2004;75(5):594-9. Crossref

86. Liu $\mathrm{X}$, Feng $\mathrm{H}$, Zhang $\mathrm{H}$, Hong L, Wang XS, Zhang J. Arthroscopic prevalence of ramp lesion in 868 patients with anterior cruciate ligament injury. Am J Sports Med 2011;39(4):832-7. Crossref

87. Bollen SR. Posteromedial meniscocapsular injury associated with rupture of the anterior cruciate ligament: a previously unrecognised association. J Bone Joint Surg $\mathrm{Br}$ 2010;92(2):222-3. Crossref

88. Sonnery-Cottet B, Conteduca J, Thaunat M, Gunepin FX, Seil R. Hidden lesions of the posterior horn of the medial meniscus: a systematic arthroscopic exploration of the concealed portion of the knee. Am J Sports Med 2014;42(4):921-6. Crossref

89. Heilpern G, Stephen J, Ball S, Amis A, Williams A. It is safe and effective to use all inside meniscal repair devices for posteromedial meniscal 'ramp' lesions. Knee Surg Sports Traumatol Arthrosc 2018. [Epub ahead of print] Crossref

90. Krause WR, Pope MH, Johnson RJ, Wilder DG. Mechanical changes in the knee after meniscectomy. J Bone Joint Surg Am 1976;58(5):599-604.

91. Newman AP, Anderson DR, Daniels AU, Dales MC. Mechanics of the healed meniscus in a canine model. Am J Sports Med 1989;17(2):164-75. Crossref

92. Bin SI, Kim JM, Shin SJ. Radial tears of the posterior horn of the medial meniscus. Arthroscopy 2004;20(4):373-8. Crossref

93. Messner K, Gao J. The menisci of the knee joint. Anatomical and functional characteristics, and a rationale for clinical treatment. J Anat 1998;193(Pt 2):161-78.

94. Hede A, Larsen E, Sandberg H. Partial versus total meniscectomy. A prospective, randomised study with longterm follow-up. J Bone Joint Surg Br 1992;74(1):118-21.

95. Ra HJ, Ha JK, Jang SH, Lee DW, Kim JG. Arthroscopic inside-out repair of complete radial tears of the meniscus with a fibrin clot. Knee Surg Sports Traumatol Arthrosc 2013;21(9):2126-30. Crossref

96. Moulton SG, Bhatia S, Civitarese DM, Frank RM, Dean CS, LaPrade RF. Surgical Techniques and Outcomes of Repairing Meniscal Radial Tears: A Systematic Review. Arthroscopy 2016;32(9):1919-25. Crossref 